
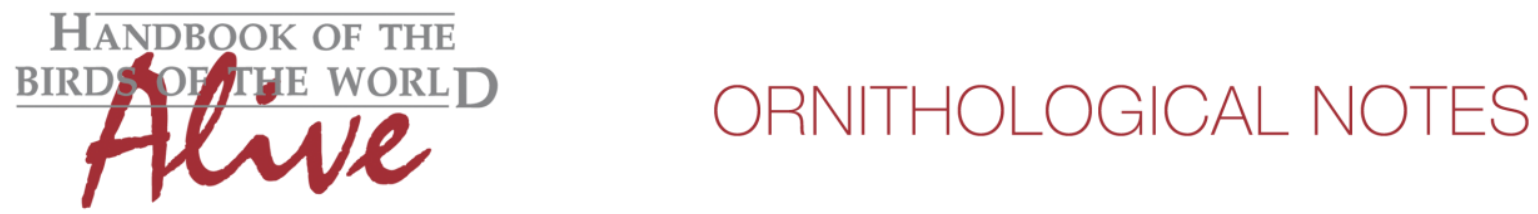

\title{
Notes on the vocalizations of Grey-crowned Babbler (Pomatostomus temporalis)
}

\section{Peter Boesman}

In the following we briefly analyze and compare voice of the two races of Grey-crowned Babbler (Pomatostomus temporalis). We also try to quantify the extent of any vocal differences using the criteria proposed by Tobias et al. (2010), as a support for taxonomic review. We have made use of sound recordings available on-line from Xeno Canto (XC) and Macaulay Library (ML), and located 16 recordings of this species, of which only 2 of the race rubeculus.

P.t.temporalis has a wide variety of vocalizations, which is not surprising given its complex social behaviour.

The song or territorial advertising call is usually given as an antiphonal duet among pairs, e.g. "yahoo..nyeh..yahoo..nyeh...", sometimes only the male is singing. Other vocalizations are different low-pitched clucking or gobbling notes, and chattering calls.

Given we have only 2 recordings of rubeculus, we have tried to find a matching vocalization of temporalis:

rubeculus (XC142615)(Presumably song of a single male)

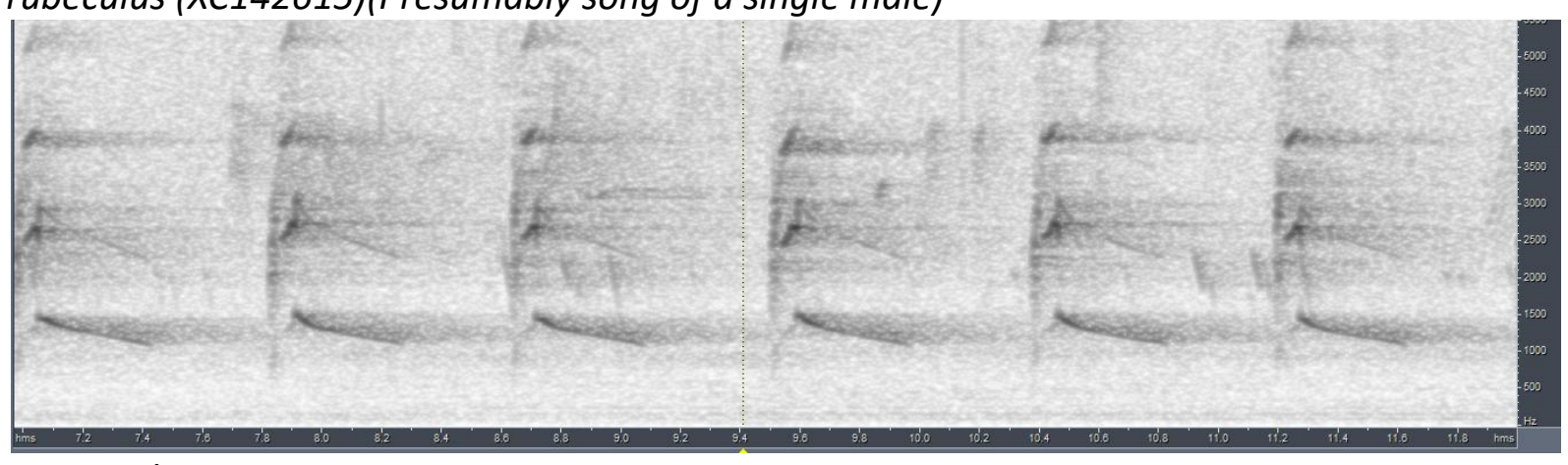

temporalis

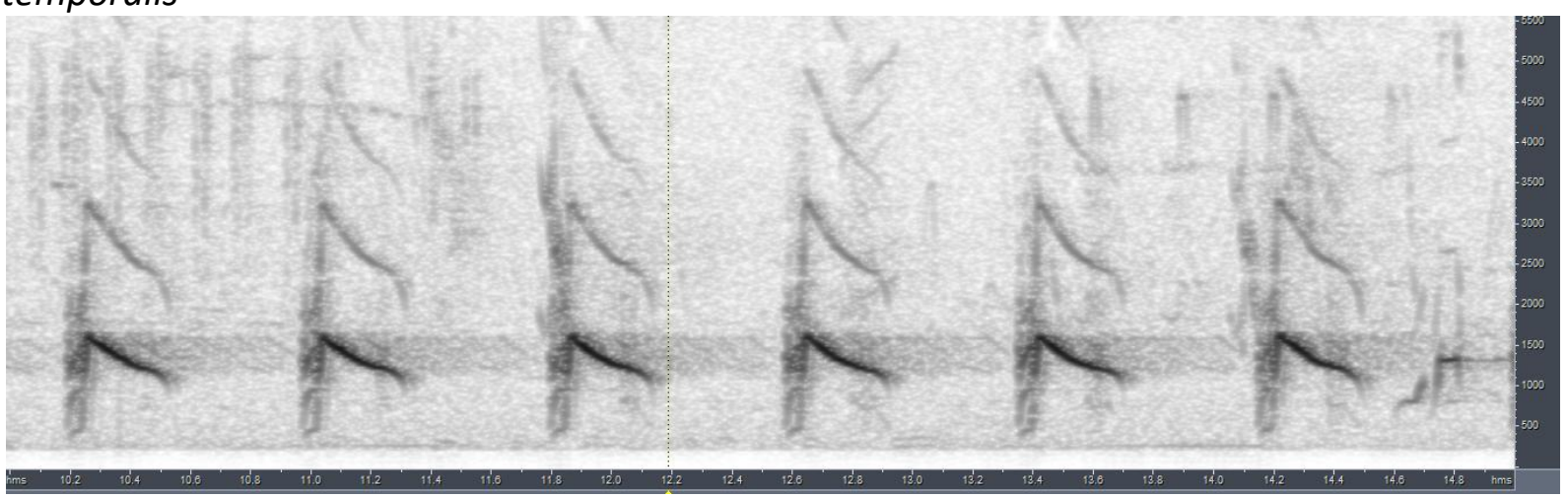

Pace, note length and pitch are similar. 

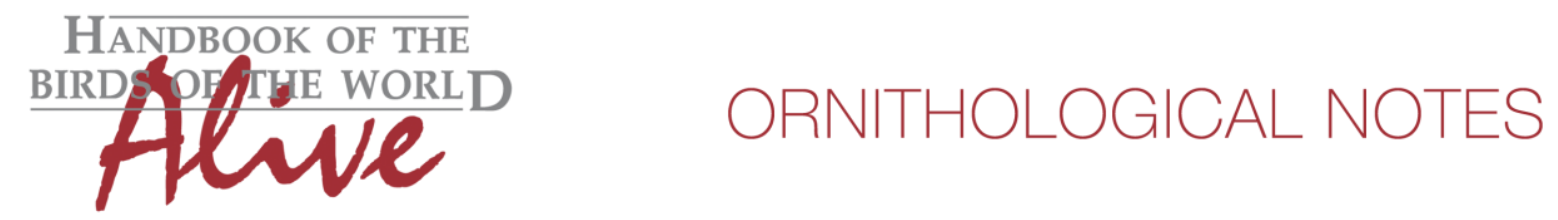

rubeculus (ML14203)(Calls of several birds vocalizing simultaneously)

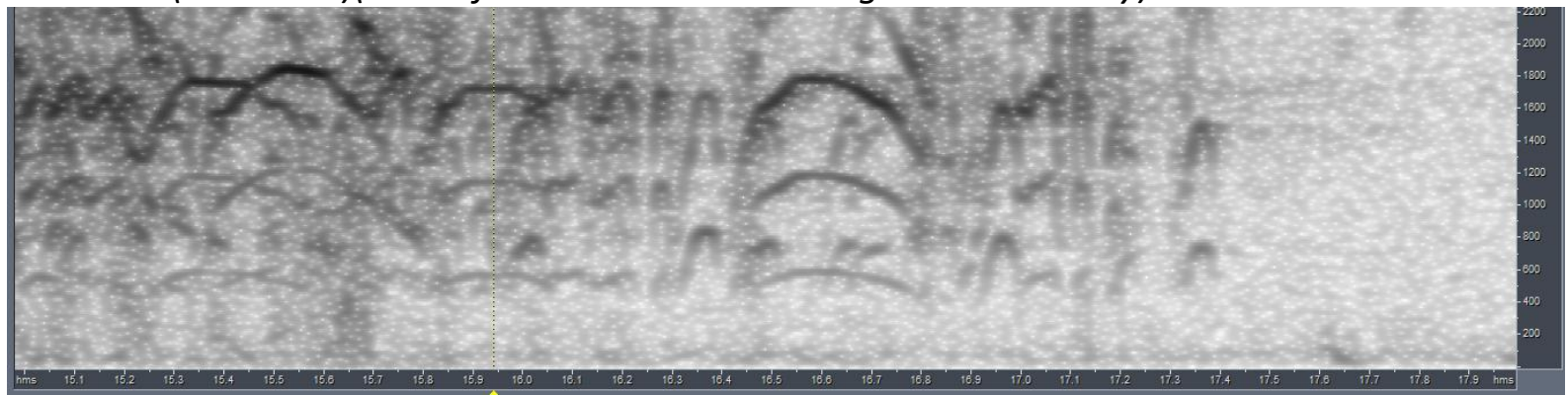

temporalis

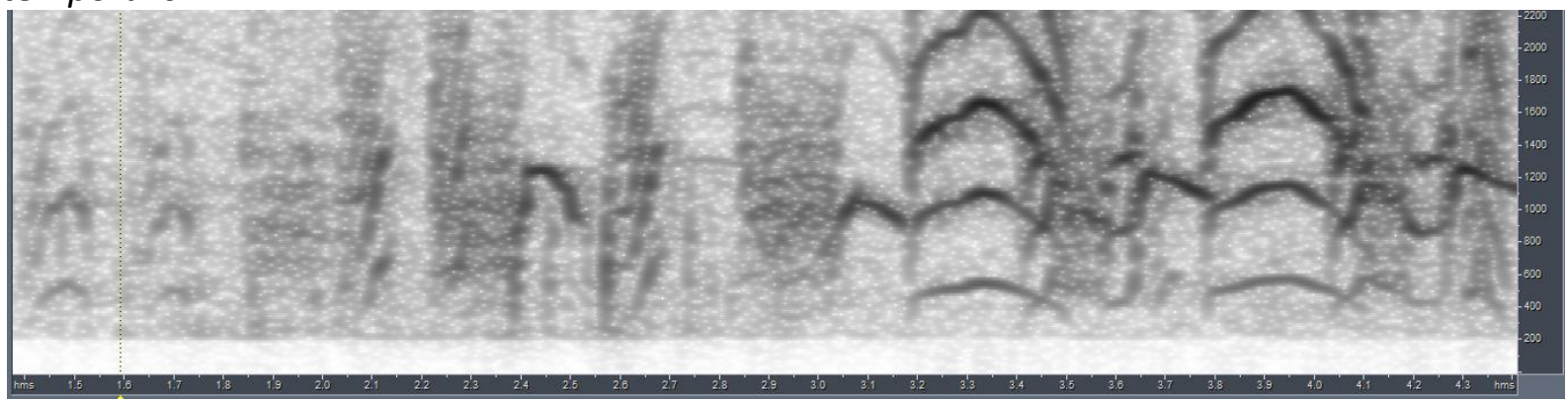

At least the short gobbling notes (overslurred), and the drawn-out nasal calls are quite similar in length and pitch.

It would thus seem that the vocalizations of both races are similar and hard to distinguish. Only a large number of recordings would allow us to check if there are any diagnostic features. In any case, an overall score for vocal difference following Tobias criteria would be (very) low.

This note was finalized on 7th September 2015, using sound recordings available on-line at that moment. We would like to thank in particular the sound recordists who placed their recordings for this species on XC and ML: Patrik Åberg, Marc Anderson, Benjamin Clock, Emma Greig, Linda Macaulay, Cedar Mathers-Winn, Mark Robbins and Fritz Trillmich.

\section{References}

Tobias, J.A., Seddon, N., Spottiswoode, C.N., Pilgrim, J.D., Fishpool, L.D.C. \& Collar, N.J. (2010). Quantitative criteria for species delimitation. Ibis 152(4): 724-746.

\section{Recommended citation}

Boesman, P. (2016). Notes on the vocalizations of Grey-crowned Babbler (Pomatostomus temporalis). HBW Alive Ornithological Note 156. In: Handbook of the Birds of the World Alive. Lynx Edicions, Barcelona. (retrieved from http://www.hbw.com/node/932086 on 17 August 2016). 